\title{
ATISBOS DE UN TIEMPO AUTENTICO PARA UNA EDUCACIÓN ESENCIAL
}

Glimpses of a real time for an essential education

Vislumbres de um tempo autentico para uma educacao esencial

\section{Enzo Arias Villarroel}

Universidad de Valparaiso, Chile. Fono: +56 9 97493794. Correo electrónico: arias.enzo@gmail.com

\section{Resumen}

La percepción del tiempo que prepondera en nuestra educación está dominada esencialmente por una representación mecánica y lineal, que concibe al tiempo como una dimensión exterior sujeta a medida, cálculo y planificación. Esta representación nos resulta tan familiar que no nos hemos preguntado si nuestra educación, es favorecida o alterada por esta perspectiva del tiempo. ¿Existe otra manera de concebir el tiempo que dé cuenta de una autentica experiencia educativa?

Palabras Clave: tiempo, medida, educación, estar presente, dejar estar presente, don.

\begin{abstract}
The perception of time that prevails in our education is essentially dominated by a mechanical and linear representation that conceives time as an external dimension, subject to measurement, calculation and planning . This representation is so familiar that we do not ask ourselves if our education is favored or altered by this time perspective. Is there another way of conceiving time that account for a real educational experience?

Key words: time, measurement, education, be present, leaving present, talent.

\section{Resumo}

A percepção predominante do tempo em educação fica dominada esencialmente por uma representacao mecánica e linear, que concebe o tempo como uma dimencao exterior, retida a medida, cálculo e planejamento. Nesta representacao torna-se familiar nao fazer perguntas si nossa educacao é favorecida, ou alterada por este perspectiva do tempo. Existe
\end{abstract}


uma outra maneira de conceber o tempo, que de conta de uma autentica experiencia educativa?

Palabras chave: tempo, medida, educacao, ficar presente, dom.

\section{ATISBOS DE UN TIEMPO AUTENTICO PARA UNA EDUCACIÓN ESENCIAL}

"El pensar solo comienza cuando hemos experimentado que la razón, tan glorificada durante siglos, es la más tenaz adversaria del pensar”. (Heidegger, 2010: 198).

Movilizado por esta cita de Martin Heidegger y guiado especialmente por sus reflexiones acerca del tiempo, deseo dar inicio a este artículo que propone pensar nuestra experiencia educativa bajo otra perspectiva del tiempo, más cercano al estudio fenomenológico que a los criterios racionales acostumbrados.

Durante siglos hemos vivido tejiendo una vida guiada por representaciones racionales y sus distinciones. Entregándonos mansamente a un mundo de imágenes que deciden el modo de pensar, de sentir y conducirse, ¿Qué podría suceder si, por lo pronto, exploramos otra mirada del tiempo?, contemplando que es una de las experiencia más próximas, sin embargo, una de las más lejanas a nuestra comprensión.

Dar otra mirada al fenómeno del tiempo significa 'darle el lugar que le corresponde' como fundamento de la existencia humana. Si la experiencia del tiempo, no está del todo esclarecida es porque vivimos dominados por una concepción del tiempo lineal que ha penetrado en todas las áreas del quehacer humano; la cultura, la economía, la organización social, la salud y, por cierto, la educación.

El tiempo se encuentra esencialmente definido por su mesurabilidad, es decir, por su disposición a ser medible, contable, planificado, etc. Representación que relaciona el tiempo al espacio, como una medida de la distancia entre un punto y otro, entre 'un ahora y otro ahora'. Lo excepcional es que esta es una consideración del tiempo mecánico materialista que exterioriza la experiencia del tiempo y deja cerrado el acceso a la dimensión donde por esencia "se da" la percepción del tiempo, a saber, la existencia humana singular del caso.

¿Qué ocurre si el tiempo es exclusivamente interpretado como una medida? 
El tiempo queda destinado como algo externo, como un 'estar fuera', que se puede planificar y asegurar. El tiempo así concebido queda 'aprehendido', 'apresado' en la maquinaria de un reloj que indica el "cuánto - tiempo" y el "desde - cuándo - hasta cuándo”.

(...) Un reloj indica el tiempo. Un reloj es un sistema físico en el que se repite constantemente la misma secuencia temporal, con la condición de que este sistema físico no esté sujeto a cambio por ningún influjo externo. La repetición es cíclica. Cada periodo tiene la misma duración temporal. El reloj ofrece una duración idéntica que se repite constantemente, una duración a la que uno siempre puede recurrir (...) Este tiempo es constantemente uniforme y homogéneo. Sólo en tanto el tiempo está constituido homogéneamente puede ser medido. (Heidegger, 1999: 2).

Lo paradójico es que aplicamos esta representación 'uniforme y homogénea' de pensar el tiempo no sólo en ámbitos mecánicos y materialistas, sino en la totalidad del mundo, cuando pareciera que hay dominios donde esta concepción no opera. Y no opera porque la existencia en ningún caso obedece a una 'repetición cíclica', excepto que se la fuerce a entrar en un modelo que premedite uniformar la experiencia. De no ser así, la existencia naturalmente se preña de vivencias únicas y singulares, sólo repetibles si pudiésemos recrear la totalidad de lo vivido.

Por lo tanto, ningún ahora es idéntico a cualquier otro, todos discurren en el fluir excepcional del presente.

- La existencia humana no discurre en una secuencia de ahoras.

- El ahora no es reductible al presente, porque él ahora está al servicio de la medida, en cambio, el presente al servicio de la manifestación.

- El 'ahora' es la abstracción de un presente, pero el presente no es una abstracción, pues siempre se trata de la existencia singular del caso.

Considerado así, el tiempo que le es propio a la educación y a la existencia humana en general ocurre en el presente, pero no como una serie de ahoras, sino como 'presencia', como algo que surge, se muestra y luego se vuelve a sumergir, inaprensible por la medida de un reloj, pues ese tiempo no tiene medida, sino que es vivencia pura. 
El tiempo en el que nuestros niños (as) son educados es un espacio distinto de la duración o del transcurrir de las manillas del reloj. Es una amplitud, una inmensidad donde el niño (a) se encuentra con una comprensión de sí mismo. Una comprensión que le viene dada por la vivencia (entendida como una matriz de sentido) y no por la transmisión de conocimientos organizados en una serie de ahoras.

Heidegger suele llamar 'apertura' a esta amplitud en que algo se regala y otros fenomenólogos la llaman 'campo'. El campo, es un surgir y un sumergirse de algo que se realiza y consuma en su aparecer, por eso mismo es un presente porque se muestra y se da brevemente.

"En presencia del campo todo se vuelve nítido y prevalece una resonancia profunda con todo lo que emerge. Lo que allí surge es reconocido como si viviera en uno y se vivencia como lo más hermoso". (Hellinger, 2008: 247).

Esta experiencia es más común de lo que imaginamos y puede exponerse a través del siguiente ejemplo; supongamos que nos encontramos mirando una película infantil junto a un grupo de niños (as), con un objetivo y una finalidad muy claros. Todo va de acuerdo a lo programado, cuando de pronto, el comentario de un niño (a) inspirado por la película hace que todo en medio de esa familiaridad se silencie, algo resuena en todos los corazones, y nos hace sentir agradecidos de estar allí. Este instante memorable e inesperado es el campo.

Hoy en día, en nuestra práctica educativa es usual vivir pasando rápidamente de una actividad a otra, de un "ahora a otro ahora" sin atender el tiempo inherente a la vivencia, como si fuese un acto insignificante. Si el tiempo de la vivencia educativa fuese verdaderamente 'uniforme y homogéneo' tal vez daría lo mismo cancelar una vivencia y retomarla posteriormente. Pero no es así, porque lo que se hace presente como vivencia es una totalidad inabarcable e irrepetible. Por lo tanto, lo cancelado se cancela para siempre.

Por eso, nuestra educación no puede estar definida por la organización y la rutina de las actividades, sino que tiene que abrirse a una concepción diferente del tiempo. Que ponga la atención en ese 'campo de apertura' donde algo se manifiesta, considerando que 
eso que 'se da' como manifestación, 'viene y va en el tiempo que le es oportuno', y no está sujeta a cálculos que arbitrariamente deciden su duración, su cuándo y hasta cuánto.

"Cada cosa tiene su tiempo. Lo que con ello se piensa es: todo lo que en cada caso es, viene y va en el tiempo que le es oportuno y permanece por un tiempo, durante el tiempo que le ha sido asignado.” (Heidegger, 2000: 21)

El tiempo en que 'cada cosa es' es el presente, pero no el presente en el sentido del ahora, sino como 'presencia', como un estar presente y un dejar estar presente, distinta a la percepción del tiempo como algo disponible, pues aquí se entiende que el tiempo no es algo que se posee, se mida o se produzca. Cuando se dice que aquello que 'es' viene y va en el tiempo que le es oportuno, se está afirmando que la presencia de algo 'se da en el tiempo’ y ello es algo que le concierne íntimamente al ser humano.

Desde esta perspectiva, es fundamental que los educadores (as) aprendan a concebir como un don el 'estar presente' y el 'dejar estar presente', pues sólo de esa manera es posible percibir lo que 'se da', como donación en el tiempo. Lo contrario, es perdurar en la percepción de lo que transcurre y se produce de acuerdo a la medida de un reloj. Mientras sigamos operando en la representación del tiempo, como un producir actividades, quedamos clausurados para la comprensión de ese don.

El ser humano tiene el don de estar presente porque existe algo que 'se da' en el ámbito abierto del tiempo y a esa relación Heidegger la llama; la regalía o la ofrenda esclarecedora.

"Denominamos al dar que se da en el tiempo autentico, la regalía esclarecedoraocultadora" (Heidegger, 2000: 35).

Esclarecedora-ocultadora porque aquello que se da en la apertura del tiempo, no permanece, sino que se sumerge en lo oculto, donde queda a resguardo del dominio del juicio y donde nadie puede agenciarse ser dueño de lo revelado. Es una vivencia, un darse cuenta y no una certeza. En ese sentido lo que 'se da' tiene también un carácter 'liberador', porque en tales condiciones, somos libres para dejar de pensar en conformidad con lo aprendido y nos libera para pensar en correspondencia con algo mucho más originario. 
Bajo esta perspectiva el educador (a) y el niño(a) se vuelven receptores de aquello que se hace presente y de algún modo son destinados a cuidar de ello en su esencia. Ambos quedan reunidos en esa regalía esclarecedora.

\section{Referencias bibliográficas}

Heidegger, M. (2010). Caminos del Bosque. Madrid: Alianza Editorial.

Heidegger, M. (1999). El concepto de tiempo. Madrid, Trotta.

Heidegger, M. (2000). Tiempo y ser. Madrid. Editorial Tecnos.

Hellinger, B. (2008). La verdad en movimiento. Buenos Aires: Editorial Alma Lepik. 